\title{
Biosynthesis of Gold Nanoparticles Using Litsea cubeba Fruit Extract for Catalytic Reduction of 4-Nitrophenol
}

\author{
Van-Dat Doan $\mathbb{D}^{1},{ }^{1}$ Anh Tai Thieu, ${ }^{2}$ Thanh-Danh Nguyen $\left(\mathbb{D},{ }^{3,4}\right.$ Van-Cuong Nguyen, \\ Xuan-Thang Cao, ${ }^{1}$ Thi Lan-Huong Nguyen, ${ }^{5}$ and Van Thuan Le $\mathbb{D}^{6,7}$ \\ ${ }^{1}$ Faculty of Chemical Engineering, Industrial University of Ho Chi Minh City, Ho Chi Minh City, Vietnam \\ ${ }^{2}$ Department of Pharmacy, Duy Tan University, 03 Quang Trung, Da Nang 50000, Vietnam \\ ${ }^{3}$ School of Biotechnology, Tan Tao University, Long An Province, Vietnam \\ ${ }^{4}$ Institute of Chemical Technology, Vietnam Academy of Science and Technology, Ho Chi Minh City, Vietnam \\ ${ }^{5}$ Institute of Biotechnology and Food Technology, Industrial University of Ho Chi Minh City, Ho Chi Minh City, Vietnam \\ ${ }^{6}$ Center for Advanced Chemistry, Institute of Research and Development, Duy Tan University, Da Nang 550000, Vietnam \\ ${ }^{7}$ The Faculty of Environmental and Chemical Engineering, Duy Tan University, Da Nang 550000, Vietnam
}

Correspondence should be addressed to Van Thuan Le; levanthuan3@duytan.edu.vn

Received 22 March 2020; Revised 27 May 2020; Accepted 10 June 2020; Published 23 June 2020

Academic Editor: Miguel A. Correa-Duarte

Copyright (C) 2020 Van-Dat Doan et al. This is an open access article distributed under the Creative Commons Attribution License, which permits unrestricted use, distribution, and reproduction in any medium, provided the original work is properly cited.

\begin{abstract}
This work describes a simple single-step method for green synthesis of colloidal gold nanoparticles (AuNPs) using Litsea cubeba (LC) fruit extract as a reducing as well as stabilizing agent simultaneously. Major parameters affecting the formation of LCAuNPs, including gold ion concentration, reaction time, and reaction temperature were optimized using ultraviolet-visible (UVVis) measurements at a characteristic maximum absorbance of $535 \mathrm{~nm}$. The functional groups responsible for reducing gold ions and capping AuNPs were examined by Fourier-transform infrared (FTIR) spectroscopy. Powder X-ray diffraction (XRD) analysis revealed the crystalline nature of AuNPs. Transmission electron microscopy (TEM) measurements showed that the biosynthesized LC-AuNPs were mostly spherical with an average size of $8-18 \mathrm{~nm}$. The nanoparticles also demonstrated excellent ultrarapid catalytic activity for the complete reduction of 4-nitrophenol to p-aminophenol in the presence of $\mathrm{NaBH}_{4}$ within 10 min with a reaction rate constant of $0.348 \mathrm{~min}^{-1}$.
\end{abstract}

\section{Introduction}

Precious metal nanoparticles, especially gold nanoparticles (AuNPs), have attracted much attention in the past decades due to their unique optical, electrical as well as biological properties, which make them widely used in many fields including optics, biosensing, imaging, drug delivery, medicine, antimicrobial, and catalysis [1-3] [4-7]. Many methods based on chemical, physical, and biological approaches have been increasingly developed for synthesizing AuNPs with controllable size, shape, and morphology [8, 9]. However, these traditional methods have posed lots of effects on human health and pressure on the environment due to the toxic compounds used in the synthesis process of AuNPs [10]. Recently, green synthesis routes using plant extracts as reducing and capping agents are more interested in the preparation of AuNPs because of their several advantages such as environmental friendliness, low cost, less chances of failure, and ease of production on an industrial scale [11]. There are many reports about the green synthesis of AuNPs from plant extracts, e.g., Fritillaria cirrhosa [12], Jasminum auriculatum leaf [13], Commiphora wightii [14], red cabbage [15], Flammulina velutipes [16], Euphorbia fischeriana root [17], and Solanum nigrum leaf [18].

Litsea cubeba (LC) - a fast-growing evergreen shrub belonging to the family of Lauraceae-grows predominantly in tropical regions of Southeast Asia, mainly in Indonesia, China, and Vietnam up to an altitude of $2700 \mathrm{~m}$ from sea level [19]. LC produces a small, pepper-like fruits, which are commonly used in traditional medicines because they 
contain several useful biologically active compounds, including alkaloids, terpenoids, flavonoids, steroids, lignans, and fatty acids [20-22]. These compounds are proved as suitable reducing and capping agents for the synthesis of AuNPs [23].

It has been reported that AuNPs exhibit strong catalytic activity for the complete hydrogenation of toxic nitrophenolic compounds to unharmful substances of respective aminophenols [24, 25]. Among them, 4-nitrophenol (4-NP) discharged mainly from fertilizer production, petrochemical, and dye-related manufacturing activities is considered a dangerous organic pollutant in industrial wastewater [26]. The catalytic reduction of 4-NP using AuNPs in the role of a catalyst has been widely studied [27, 28]. It is also well known that the reduction reaction of nitrophenols with $\mathrm{NaBH}_{4}$ in the absence of catalysts is thermodynamically favorable, but kinetically unfavorable because of the kinetic barrier between the used reactants. With the presence of metallic nanoparticles, especially AuNPs, this kinetic barrier can be overcome via an electron transfer mechanism of the catalyst. Herein, both borohydride and nitrophenolate ions played the role of electron donors and acceptors on the catalyst surface, respectively [29].

In this work, a novel single-step synthesis of AuNPs from chloroaurate ions $\left(\mathrm{AuCl}_{4}^{-}\right)$and the aqueous extract of $\mathrm{LC}$ fruits has been demonstrated. The prepared AuNPs were characterized by transmission electron microscopy (TEM), scanning electron microscopy (SEM), powder X-ray diffraction (XRD), thermogravimetric analysis (TGA), UV-Vis spectroscopy, and energy-dispersive X-ray (EDX) spectroscopy. The catalytic activity of the biosynthesized AuNPs toward the reduction of 4-NP using $\mathrm{NaBH}_{4}$ solution was also evaluated.

\section{Experimental}

2.1. Materials and Chemicals. Hydrogen tetrachloroaurate (III) hydrate $\left(\mathrm{HAuCl}_{4} \cdot 3 \mathrm{H}_{2} \mathrm{O}, 99.9 \%\right)$ was purchased from Acros Organics (Belgium). Sodium tetrahydridoborate $\left(\mathrm{NaBH}_{4}, 99 \%\right)$ and 4-nitrophenol $\left(\mathrm{C}_{6} \mathrm{H}_{5} \mathrm{NO}_{3}, \geq 99 \%\right)$ were supplied by Sigma-Aldrich. All chemicals were of reagent grade and used without any purification. LC fruits were collected from a local forest in Quang Nam Province (Vietnam) in July.

2.2. Preparation of LC Fruit Extract. Litsea cubeba fresh fruits were washed thoroughly to remove all the dirt, dried up at $50^{\circ} \mathrm{C}$ for three days, and ground up into fine powder before use. The powder of LC fruits $(10 \mathrm{~g})$ was soaked in distilled water $(400 \mathrm{~mL})$ at $90^{\circ} \mathrm{C}$ with reflux for $1 \mathrm{~h}$. The obtained extract was cooled down to room temperature and then filtered with Whatman filter paper No. 1 to remove any plant debris. The extract was stored at $4^{\circ} \mathrm{C}$ in a refrigerator for further experiments.

2.3. Synthesis of AuNPs. Synthesis of biogenic AuNPs was performed with $\mathrm{HAuCl}_{4}$ solution and aqueous LC fruit extract. Briefly, $1 \mathrm{~mL}$ of the extract was mixed with $20 \mathrm{~mL}$ of $\mathrm{Au}^{3+}$ ion solution under vigorous stirring in the dark to avoid any undesirable photochemical reaction for newly formed AuNPs. The change in color of the solution after the reaction completed acted as a visual sign for the success of the synthesis process. Factors that affect the synthesis process, including gold ion concentration $(0.5-2 \mathrm{mmol} / \mathrm{L})$, reaction time $(30-80 \mathrm{~min})$, and reaction temperature $\left(30-80^{\circ} \mathrm{C}\right)$, were also investigated to determine the optimal conditions. The optimization was performed using UV-Vis measurements on an Evolution $300 \mathrm{UV}$-Vis spectrophotometer with the characteristic maximum absorption peak of AuNPs at around $535 \mathrm{~nm}$. The obtained AuNPs under optimal conditions were centrifuged and dried up until constant mass before use to study their physicochemical characteristics and catalytic activity. The biosynthesis procedure of AuNPs using LC fruit extract is illustrated in Scheme 1.

2.4. Characterization of AuNPs. The possible functional groups presented in the LC fruit extract and AuNPs were examined by Fourier-transform infrared (FTIR) spectroscopy in the range of $4000-500 \mathrm{~cm}^{-1}$ on a Bruker Tensor 27 (Germany). The crystalline structure and composition of AuNPs were analyzed using a powder X-ray diffraction (XRD) method on a Shimadzu 6100 X-ray diffractometer (Japan) operating at the voltage of $40 \mathrm{kV}$, the current of $30 \mathrm{~mA}$ with $\mathrm{CuK} \alpha$ radiation at the wavelength of $1.5406 \mathrm{~nm}$, scanning speed of $0.05^{\circ} / \mathrm{s}$, and step size of $0.02^{\circ}$ in the range $2 \theta$ from $10^{\circ}$ to $80^{\circ}$. The morphology and particle size of the AuNPs in colloidal solution form were determined by a transmission electron microscope (TEM) on a JEOL JEM-1400 (Japan) at an accelerated voltage of $120 \mathrm{kV}$. The morphology of powdered AuNPs was also examined by field-emission scanning electron microscopy (FE-SEM) on a Hitachi S-4800 HI-9057-0006 (Japan) at an accelerating voltage of $10 \mathrm{kV}$. The content of gold and organic matrix acted as a capping agent for AuNPs was determined by thermogravimetric analysis (TG and DTA) using a Setaram Labsys Evo S60/58988 thermoanalyzer (France) in a range of $30-800^{\circ} \mathrm{C}$ and with a heating rate of $10^{\circ} \mathrm{C} \cdot \mathrm{min}^{-1}$ in atmosphere air. Determination of chemical elemental composition of the powdered AuNPs was performed by energy-dispersive X-ray (EDX) spectroscopy on a Horiba EMAX Energy EX400 analyzer (Japan). The dynamic scattering diameter and zeta potential of AuNPs in colloidal solution were examined on a Horiba SZ-100 (Japan) using dynamic light scattering (DLS) technology. The characterization of AuNPs and the reduction of $4-\mathrm{NP}$ were confirmed by using $\mathrm{UV}-\mathrm{V}$ is spectroscopy.

2.5. Catalytic Activity of AuNPs. The catalytic performance of LC-AuNPs was evaluated via a reduction reaction of 4-NP using $\mathrm{NaBH}_{4}$ as a reducing agent. The reaction was carried out in a quartz cell with an optical path length of $10 \mathrm{~mm}$ and capacity of $3.5 \mathrm{~mL}$ at ambient temperature. Briefly, the solution of 4 -AP $(2.5 \mathrm{~mL}$ of $0.1 \mathrm{mmol} / \mathrm{L})$ was mixed with $\mathrm{NaBH}_{4}(0.5 \mathrm{~mL}$ of $0.1 \mathrm{~mol} / \mathrm{L})$, and then, AuNPs $(3 \mathrm{mg})$ were added. The catalytic activity was examined by UV-Vis spectroscopy at the wavelength ranging from 300 to $600 \mathrm{~nm}$. A linear kinetic equation of $\ln \left(A_{t}\right)=-k t+\ln \left(A_{o}\right)$, where $k$ is the rate constant, $t$ is the reaction time, and $A_{o}$ and $A_{t}$ are the concentration of 4-NP at the initial and time $t$, 


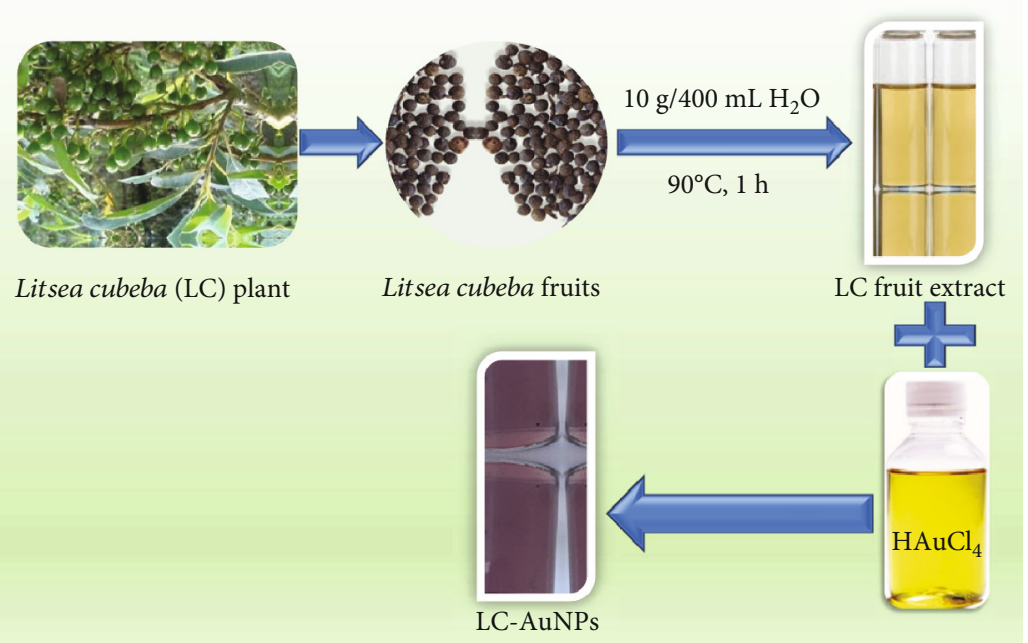

Scheme 1: The synthesis procedure of AuNPs using Litsea cubeba fruit extract.

respectively, was applied to determine the reaction rate constant via slope of linear regression of $\ln \left(A_{t}\right)$ over reaction time $t[30]$.

\section{Results and Discussion}

3.1. Synthesis of AuNPs. After adding $\mathrm{HAuCl}_{4}$ solution to the LC fruit extract, the color of the obtained mixture changed from pale yellow to purple due to the formation of AuNPs. A phytochemical-driven reaction was supposed to be the formation mechanism of AuNPs. The phytochemicals present in LC fruit extract, including alkaloids, flavonoids, amides, lignans, and steroids, may act as reducing agents for $\mathrm{Au}^{3+}$ ion conversion into $\mathrm{Au}^{0}$, followed by the agglomeration process of $\mathrm{Au}$ atoms to nanosized particles. The obtained AuNPs were immediately stabilized by the phytochemical residues to give spherical AuNPs. To control AuNPs size, three main synthesis conditions including concentration of gold ions, reaction temperature, and reaction time need to be investigated. The change in color of AuNP solution due to the localized surface plasmon resonance (SPR) along with the presence of the characteristic UV-Vis peak at $535 \mathrm{~nm}$ served as a visual inspection method for the optimization [31].

In this study, the effect of the gold ion concentration on the formation of AuNPs was investigated by adjusting the concentration of the $\mathrm{HAuCl}_{4}$ solution in the range of 0.5 $2.0 \mathrm{mmol} / \mathrm{L}$, while the reaction temperature and reaction time were kept constant at $45^{\circ} \mathrm{C}$ and $60 \mathrm{~min}$, respectively (Figure 1(a)). It can be seen that all spectra exhibit an absorption peak around $535 \mathrm{~nm}$, which is attributed to the SPR band of the AuNPs, and the concentration of gold ions strongly affects the formation of AuNPs. The increase in gold ion concentration led to the higher UV-Vis absorbance. However, at the gold ion concentration greater than $1.5 \mathrm{mmol} / \mathrm{L}$, a slight shift of maximum wavelength toward larger values was observed, indicating the formation of larger size AuNPs. Therefore, the appropriate concentration of $\mathrm{HAuCl}_{4}$ necessary to form more stable AuNPs was chosen to be $1.5 \mathrm{mmol} / \mathrm{L}$.
To optimize reaction time for the synthesis of AuNPs, after the selected time interval, the AuNP solution $(2.5 \mathrm{~mL})$ prepared at $45^{\circ} \mathrm{C}$ and $1.5 \mathrm{mmol} / \mathrm{L}$ of $\mathrm{Au}^{3+}$ was taken out to perform UV-Vis measurement. As seen in Figure 1(b), as the reaction time from $30 \mathrm{~min}$ to $60 \mathrm{~min}$ increases, the intensity of the characteristic UV-Vis peak for AuNPs increased gradually and reached a maximum after $60 \mathrm{~min}$. When the synthesis time lasted up to 80 minutes, the UV-Vis absorbance significantly decreased; this may be due to the agglomeration of newly formed AuNPs [10]. Therefore, the reaction time of 60 min was established to perform further synthesis of AuNPs.

Finally, the optimum reaction temperature was investigated in the range of $30-80^{\circ} \mathrm{C}$, while the concentration of $\mathrm{Au}^{3+}$ and reaction time were kept constant $(1.5 \mathrm{mmol} / \mathrm{L}$ and $45 \mathrm{~min}$ ). The obtained results shown in Figure 1(c) indicate that the reaction temperature also significantly affected the formation of AuNPs. The increased temperature to $45^{\circ} \mathrm{C}$ provided a suitable amount of energy to $\mathrm{Au}^{3+}$ ions for their conversion into nanoparticles. At higher temperatures, the $\mathrm{Au}$ ions could move faster, and the number of effective collisions might increase rapidly, resulting in partial coagulation of newly formed nanoparticles with a larger size, causing a decrease in optical density [22]. Therefore, the temperature of $45^{\circ} \mathrm{C}$ was chosen as optimum for the synthesis of AuNPs.

\subsection{Characterization of AuNPs}

3.2.1. Structural and FTIR Spectral Analysis. The features of crystalline structures of the biosynthesized AuNPs were determined by XRD patterns, as presented in Figure 2(a). The XRD pattern of AuNPs shows characteristic peaks at $2 \theta$ angles of $38.12^{\circ}, 44.27^{\circ}, 64.42^{\circ}$, and $77.47^{\circ}$, which are indexed for (111), (200), (220), and (311) planes of the face-centered cubic structure of $\mathrm{Au}$ corresponding with ICDD PDF card number 00-004-0784. In particular, the highest diffraction peak of AuNPs at $2 \theta$ angle about $38.12^{\circ}$ indicated that the crystals have a preferred growth direction in the plane (111). The average crystal size of AuNPs 


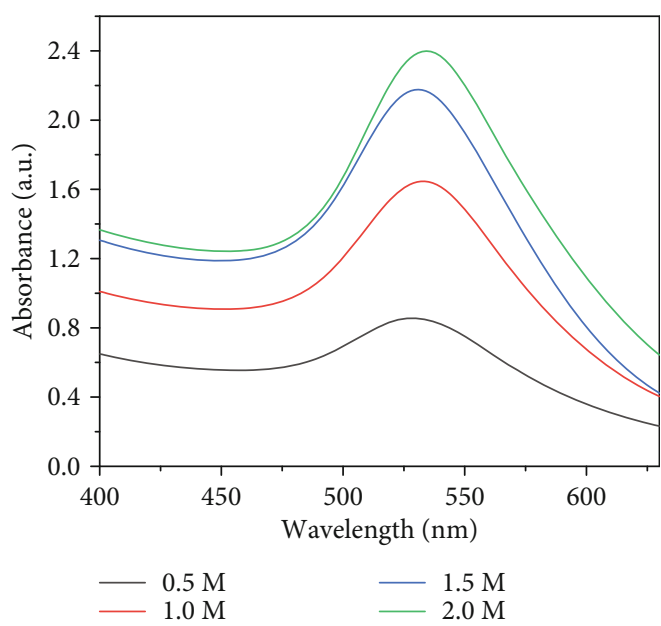

(a)

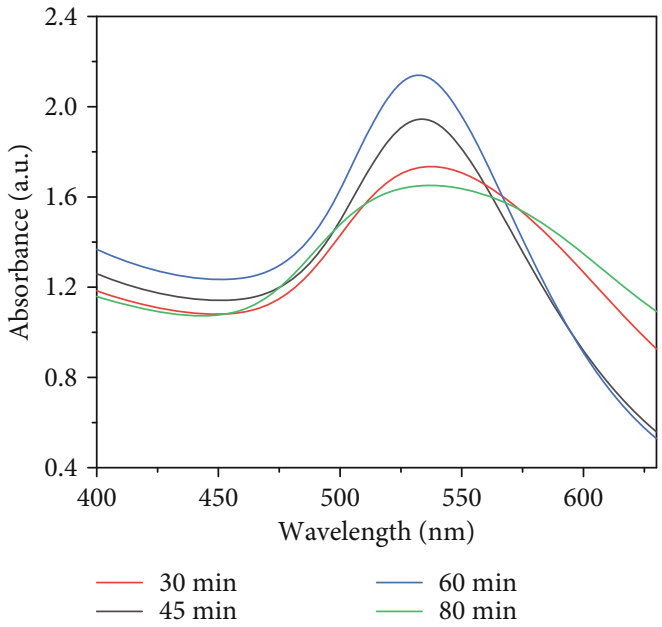

(b)

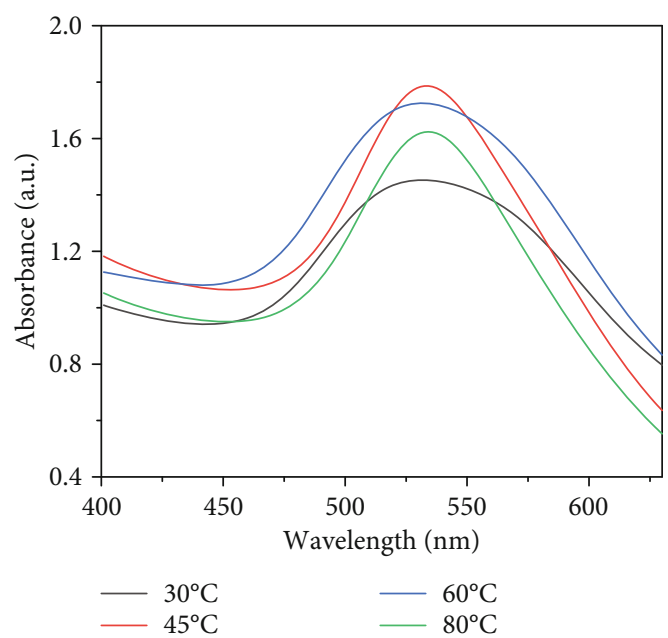

(c)

FIGURE 1: The UV-Vis absorption spectra of LC-AuNPs synthesized at (a) different concentrations of $\mathrm{HAuCl}_{4}$, (b) different reaction time, and (c) different reaction temperatures.

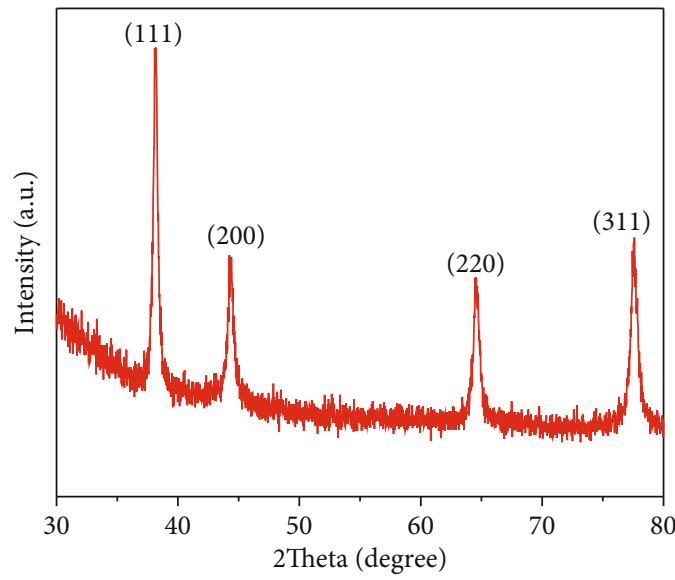

(a)

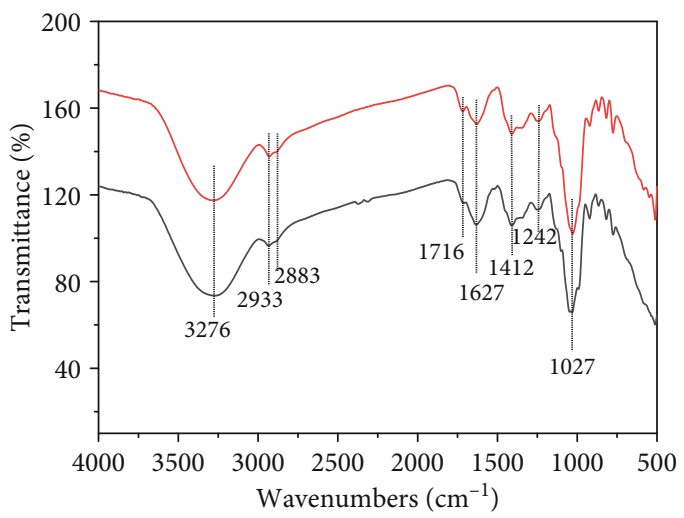

— Litsea cubeba fruit extract capped AuNPs _ L Litsea cubeba fruit extract

(b)

FIGURE 2: (a) XRD pattern of biosynthesized AuNPs, and (b) FTIR spectra of LC fruit extract and LC fruit extract-capped AuNPs. 


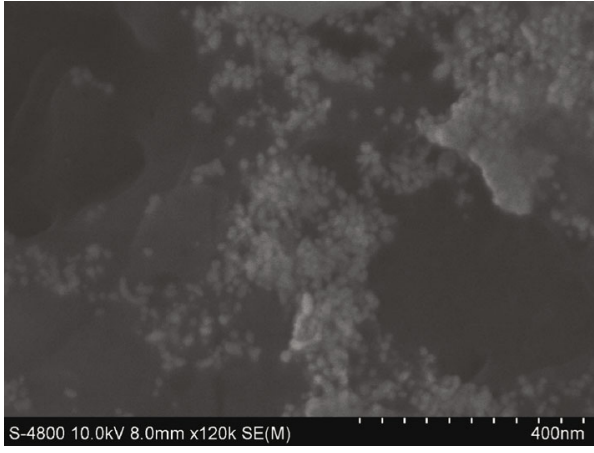

(a)

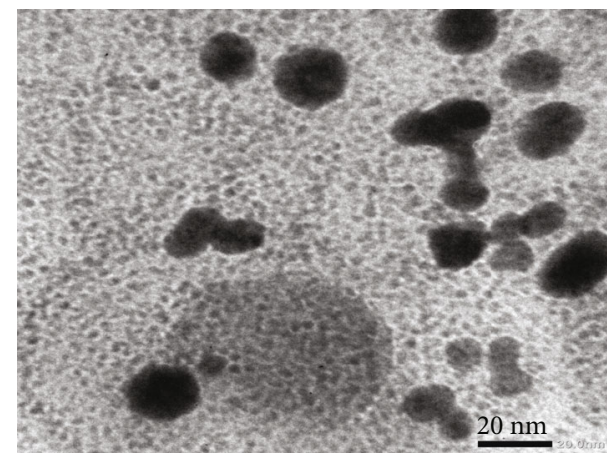

(b)

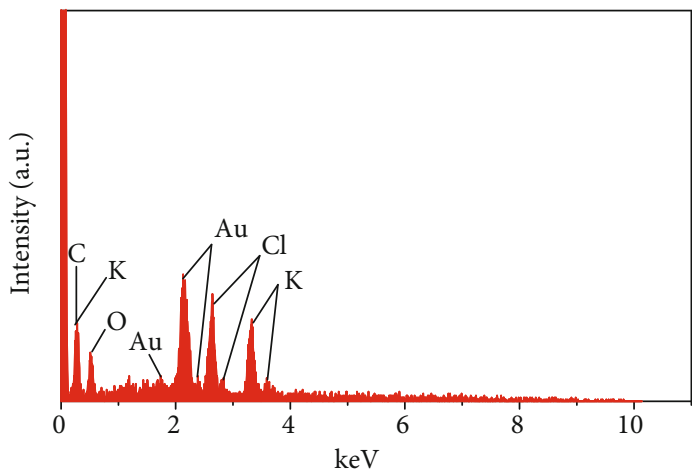

(c)

Figure 3: SEM (a) and TEM (b) images and EDX spectrum (c) of biosynthesized AuNPs.

calculated by the Debye-Scherrer equation according to this (111) plane was found to be $15.1 \mathrm{~nm}$.

The FTIR spectra of dried extract from LC fruit and LC fruit extract-capped AuNPs are shown in Figure 2(b). The FTIR spectra of both samples indicated the similarity in absorption bands. The broad bands centered at $3276 \mathrm{~cm}^{-1}$ are assigned to the stretching vibrations of $\mathrm{O}-\mathrm{H}$ groups of alkaloids, flavonoids, lignans, and steroids presented in the extract, as reported in [20, 32]. The peaks at 2933 and $2883 \mathrm{~cm}^{-1}$ are associated with $\mathrm{C}-\mathrm{H}$ stretching vibrations of $-\mathrm{CH}_{3}$ and $-\mathrm{CH}_{2}$ - bonds [33]. The peaks at 1716 and $1627 \mathrm{~cm}^{-1}$ correspond to ketone acyclic stretch and aromatic $\mathrm{C}=\mathrm{C}$ bond stretching, respectively [34]. The peak at $1412 \mathrm{~cm}^{-}$ ${ }^{1}$ is related to $-\mathrm{C}=\mathrm{C}$ - of aromatic bond stretching [35]. The peaks at 1242 and $1028 \mathrm{~cm}^{-1}$ are identified with aromatic $\mathrm{C}-\mathrm{O}$ and aliphatic $\mathrm{C}-\mathrm{O}$ band stretching related to the cyclic nature of ether and the carboxylic acid functional group, respectively [36].

3.2.2. Morphological and Compositional Studies. The SEM and TEM micrographs of AuNPs are shown in Figures 3(a) and 3(b), respectively. As it can be seen, the biosynthesized AuNPs are mostly spherical in shape and dispersed well in the aqueous solution of LC fruit extract. The colloidal AuNPs have TEM particle size ranging from 10 to $18 \mathrm{~nm}$ and are located separately. The SEM image (Figure 3(a)) also confirmed that no aggregation occurred for the biosynthesized AuNPs due to the surrounding matrix of LC fruit extract that acted as an excellent capping agent. The chemical element composition of LC fruit extract-capped AuNPs analyzed by
EDX spectroscopy is presented in Figure 3(c). The EDX spectrum revealed that the biosynthesized AuNPs are mainly composed of $\mathrm{Au}(33.94 \%)$ with characteristic peaks at 1.74 and $2.195 \mathrm{keV}$. Carbon (28.42\%) and oxygen $(9.73 \%)$ were also observed at 0.255 and $0.53 \mathrm{keV}$, respectively, confirming the presence of phytoconstituents of LC fruit extract-capped on AuNPs. Besides, inorganic elements of K (14.65\%) and Cl (13.26\%) were also found. The presence of $\mathrm{K}$ and $\mathrm{Cl}$ elements in many plant extracts has been reported in several previous works $[23,30]$.

3.2.3. Dynamic Light Scattering and Zeta Potential Study. In comparison with the dried AuNP core inside LC-capped AuNPs examined by TEM microscopy, hydrodynamic AuNPs in the aqueous extract have a bigger average size of about $65 \mathrm{~nm}$ (Figure 4(a)). The difference in the size of TEM-measured AuNPs and hydrodynamic LC-capped AuNPs revealed that the biosynthesized AuNPs are surrounded by a thick layer of organic molecules, which play a role in separating AuNPs from agglomeration and coagulation processes. The stability of colloidal AuNPs was evaluated through their zeta potential value (Figure 4(b)). As seen in Figure 4(b), the biosynthesized colloidal AuNPs are negatively charged with a small zeta potential of $-3.6 \mathrm{mV}$. It is noted that there are two main stabilization mechanisms for the formed AuNPs in the aqueous extract. The first mechanism is based on the electrostatic interaction between charged AuNPs. A zeta potential value greater than $30 \mathrm{mV}$ is required for colloidal AuNP suspension to be physically stable by a strong repulsion between two charged particles 


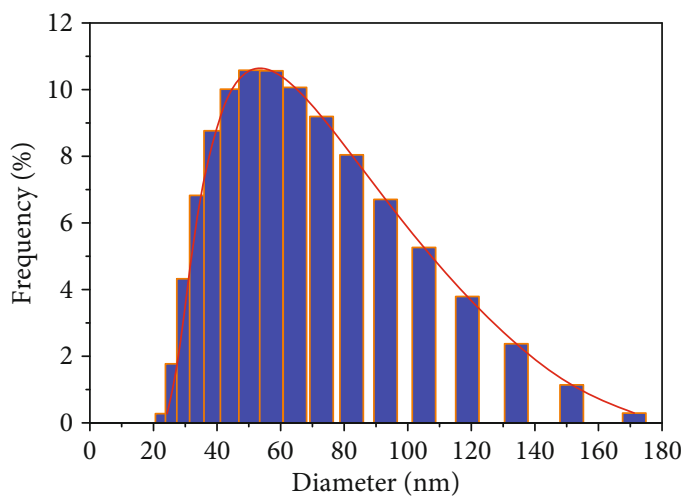

(a)

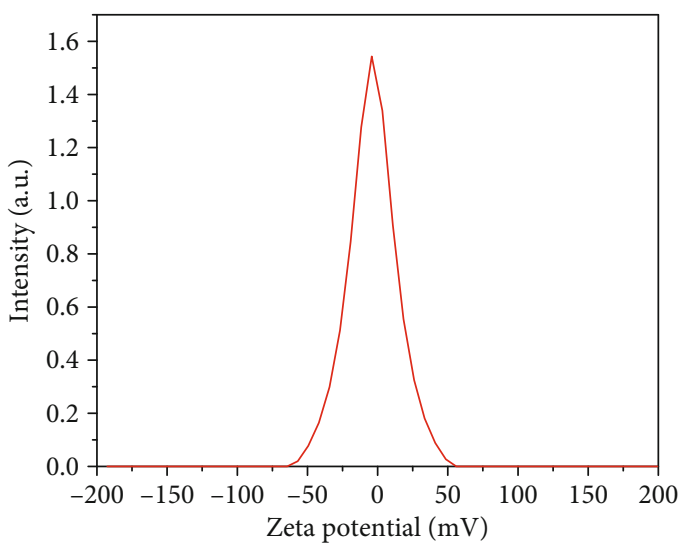

(b)

FIGURE 4: Dynamic light scattering diameter distributions (a) and zeta potential (b) of biosynthesized AuNPs.

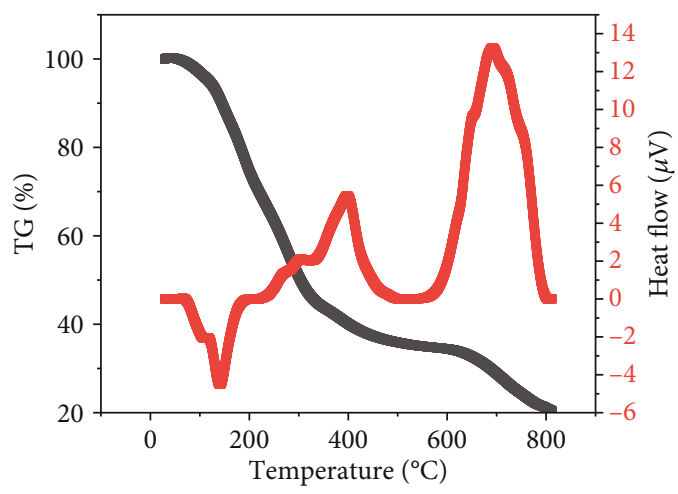

(a)

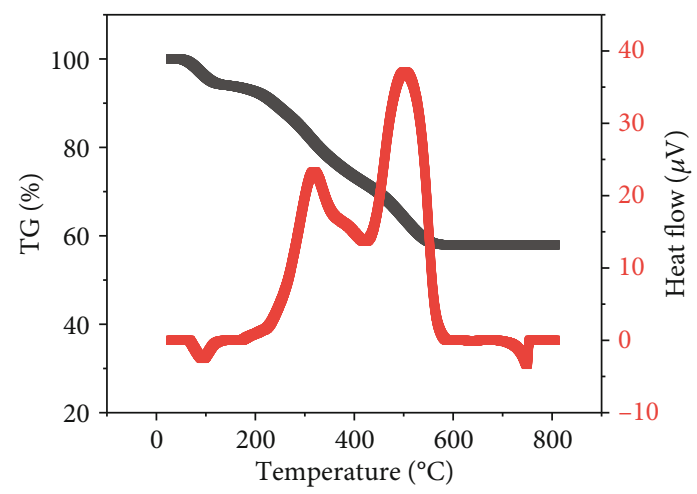

(b)

FIgURE 5: Thermogravimetric analysis of LC fruit extract (a) and LC-capped AuNPs (b).

with the same sign. The second mechanism is related to the steric effect of big organic molecules presented in the aqueous extract [35]. These organic molecules act as a protective layer to prevent nanoparticles from sticking together. The colloidal AuNP solution was observed to be stable over three weeks without any changes in color or coagulation. Therefore, it can be concluded that the AuNPs biosynthesized with LC fruit extract are mainly stabilized under steric conditions by phytochemical constituents adsorbed on the nanoparticle surface. The small zeta potential value of $-3.6 \mathrm{mV}$ of LCAuNPs may be due to polar functional groups of organic molecules such as fatty acids that existed in the LC fruit extract.

3.2.4. Thermogravimetric Analysis. The total amount of phytochemical constituents acted as a capping agent for AuNPs, and their thermal behaviors were analyzed by TGA analysis in the atmosphere air. TG-DTA curves of dried extract from LC fruit and LC fruit extract-capped AuNPs are given in Figures 5(a) and 5(b), respectively. As illustrated in Figure 5, the weight loss of about $40 \%$ for dried extract and $10 \%$ for LC-AuNPs was observed in the first temperature region ranging from room temperature to $220^{\circ} \mathrm{C}$. The initial weight loss was due to the evaporation of volatile compounds presented in LC fruit extract. In the temperature region between 220 and $600^{\circ} \mathrm{C}$, the next dominant weight loss of $28 \%$ for dried extract and $31 \%$ for AuNPs was recorded. Herein, the thermal decomposition of AuNPs can be generally associated with the pyrolysis of organic molecules capped on AuNP surface [37]. At the temperature above $600^{\circ} \mathrm{C}$, the TGA curve of AuNPs was almost unchanged, indicating that the biosynthesized AuNPs consisted of approximately $59 \%$ of gold and $41 \%$ of phytochemical constituents. The percentage superiority of gold in LC-AuNPs determined by TGA compared to that by an EDX method may be due to the centrifugation step in the synthesis process. The centrifugation of solid AuNPs purified water-soluble $\mathrm{K}^{+}$and $\mathrm{Cl}^{-}$ions. Thus, the thermal behavior of AuNPs indicates that the organic layer from LC fruit extract is mainly responsible for the stabilization of the nanoparticles.

3.3. Catalytic Activity of LC-AuNPs for the Reduction of 4Nitrophenols. It is well known that 4-NP is difficult to be completely degraded; meanwhile, its reduction product of nontoxic 4-aminophenol (4-AP) is widely applicable in medicine, especially for organic synthesis reaction of numerous drugs such as paracetamol and phenacetin [38]. As reported in $[39,40]$, the catalytic reduction of $4-\mathrm{NP}$ into 4 -AP by 


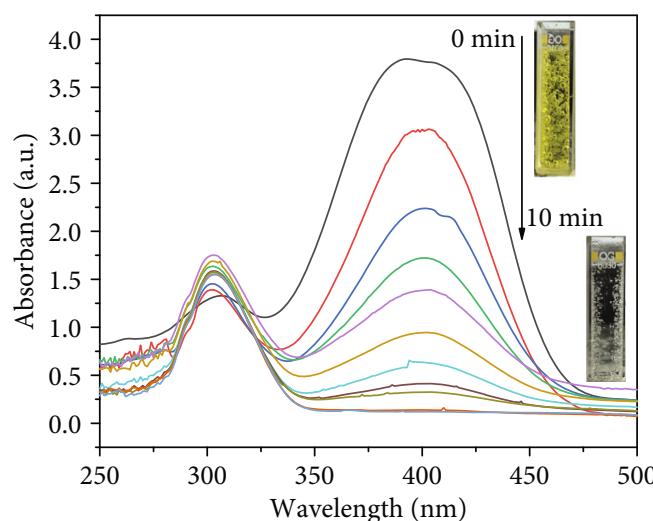

(a)

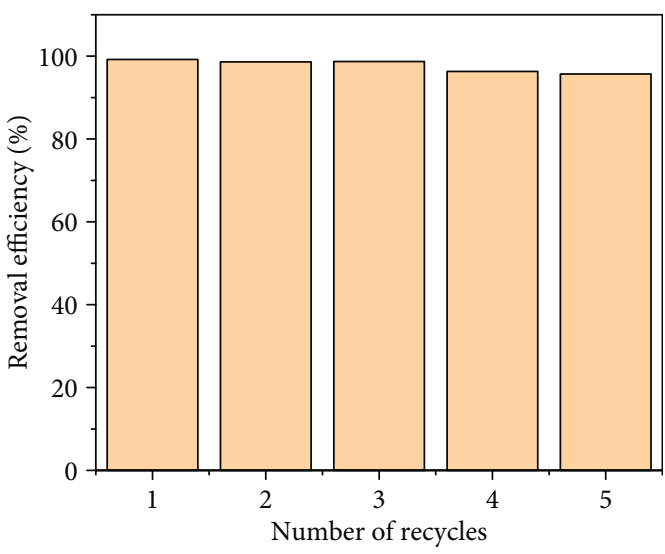

(c)

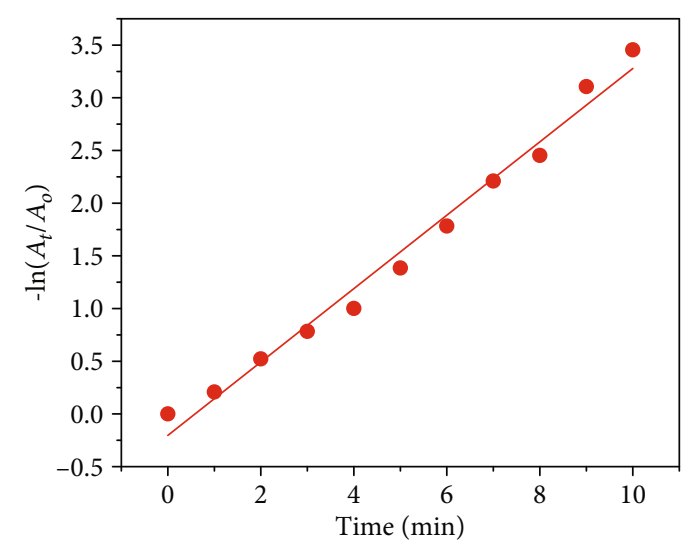

(b)

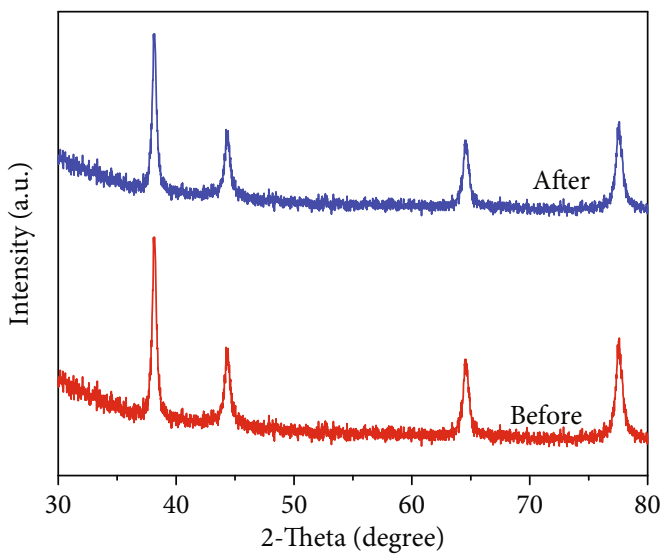

(d)

FIgURE 6: (a) UV-Vis absorption spectra recorded during the reduction of 4-NP with $\mathrm{NaBH}_{4}$ catalyzed by biosynthesized AuNPs, (b) the plot of $-\ln \left(A_{t} / A_{o}\right)$ versus time for the reduction of 4-NP, (c) recycle ability of AuNPs, and (d) XRD patterns of biosynthesized AuNPs before and after five recycles.

$\mathrm{NaBH}_{4}$ using AuNPs as a catalyst followed the LangmuirHinshelwood kinetic model. The mechanism was briefly described as follows. First, the reactants rapidly moved to the surface of AuNPs and a reversible adsorption process was established. The catalytic reduction took place on the heterogenous catalyst surface; thus, its reaction rate depended on the adsorbed amount of reactants. Second, an electron transport between $4-\mathrm{NP}$ and $\mathrm{NaBH}_{4}$ happened at the active sites of AuNPs, resulting in the productions of 4AP. When the concentration of 4-AP was high enough, desorption of 4-AP occurred, and 4-AP molecules will be released from the surface of AuNPs. Vacant active sites of AuNP surface resumed the adsorption process of 4-NP, and a new cycle of the reduction will be continued. In this study, the used amount of $\mathrm{NaBH}_{4}$ far exceeded the concentration of pollutants $\left(0.5 \mathrm{~mL}\right.$ of $0.1 \mathrm{~mol} / \mathrm{L} \mathrm{NaBH}_{4}$ vs. $2.5 \mathrm{~mL}$ of $0.1 \mathrm{mmol} / \mathrm{L}$ of $4-\mathrm{NP}$ ), so the concentration of $\mathrm{NaBH}_{4}$ could be considered a constant during the reaction. In this regard, the reaction was considered a pseudofirst-order one in which the kinetics was described by the linear equation $\ln \left(A_{t}\right)=$ $-k t+\ln \left(A_{o}\right)$.

As shown in Figure 6(a), the mixture of 4-NP and $\mathrm{NaBH}_{4}$ has yellow color with a characterized UV-Vis absorption peak at $400 \mathrm{~nm}$ due to the formation of 4-nitrophenolate ions [39]. Without the catalyst, the reduction did not occur with the evidence of an unchanged absorbance peak at $400 \mathrm{~nm}$. Upon adding AuNPs, the yellow color gradually faded, the absorbance at $400 \mathrm{~nm}$ quickly decreased, and a new UV-Vis absorption peak of 4 -AP at about $300 \mathrm{~nm}$ appeared. The reduction reaction completely finished within 10 min with reaction rate constant $k$ calculated from the plot of $-\ln \left(A_{t} / A_{o}\right)$ versus time (Figure $\left.6(\mathrm{~b})\right)$ of $0.348 \mathrm{~min}^{-1}$. The obtained reaction rate constant was higher than that of AuNPs reported in several works (Table 1). It was noted that a thick layer of organic molecules surrounding the biosynthesized LC-AuNPs could affect the catalytic activity by partially blocking the active sites of the nanoparticles. It could be the reason of the difference in catalytic performance of AuNPs (with the same particles size) biosynthesized by various biological systems.

The long-term use of AuNPs as a catalyst is an important factor for effective practical application. For the recycle process, the catalyst sample after each usage was centrifuged, washed with distilled water and ethanol, and dried for the next cycle of catalysis. The results of recycle ability toward 4-NP as well as the changes in XRD patterns of the catalyst after five catalytic cycles are presented in Figures 6(c) and $6(d)$, respectively. Figure $6(\mathrm{c})$ showed that the catalytic 
TABLE 1: Comparison of reaction rate constant $k$ with other AuNPs toward the catalytic reduction of 4-NP.

\begin{tabular}{lccc}
\hline Biological system & Particle size $(\mathrm{nm})$ & $k\left(\mathrm{~min}^{-1}\right)$ & Reference \\
\hline $\begin{array}{l}\text { Trichosporon } \\
\text { montevideense }\end{array}$ & $12-53$ & 0.032 & {$[41]$} \\
Jujube & $8-13$ & 0.070 & {$[39]$} \\
$\begin{array}{l}\text { L. indica leaf } \\
\text { Magnusiomyces }\end{array}$ & 14.5 & 0.078 & {$[37]$} \\
ingens LH-F1 & 28.3 & 0.092 & {$[42]$} \\
Crinum latifolium leaf & 17.6 & 0.206 & {$[43]$} \\
Coffea arabica seed & $16-22$ & 0.313 & {$[32]$} \\
Litsea cubeba fruit & $8-18$ & 0.348 & This \\
Breynia rhamnoides & 25 & 0.564 & {$[34]$} \\
\hline
\end{tabular}

performance were almost unchanged after the first three cycles and slightly decreased after the fifth recycle from $98.6 \%$ to $96.2 \%$. It was also observed that the XRD spectra of LC-AuNPs showed no change in the peak position and the intensity before and after catalysis, confirming the stability of LC-AuNPs in crystalline nature for a long-term use.

\section{Conclusions}

In summary, spherical AuNPs with the small TEM particle size of $8-18 \mathrm{~nm}$ were successfully biosynthesized by a green single-step route without using any expensive commercial reductants and stabilizers. This work demonstrated the efficacy of Litsea cubeba fruit extract in reducing gold ions and stabilizing AuNPs. The colloidal AuNPs are well dispersed and stable in the solution over three weeks. The obtained AuNPs also exhibited enhanced catalytic performance toward the degradation of toxic 4-NP. In addition, the reusability studies demonstrated that the LC-AuNPs retained good catalytic activity even after five cycles of reaction. Therefore, the biosynthesized AuNPs can be considered an effective catalyst in eco-friendly treatments of organic pollutants.

\section{Data Availability}

The data used to support the findings of this study are included within the article.

\section{Conflicts of Interest}

The authors declare that they have no conflicts of interest.

\section{Acknowledgments}

This research is funded by Vietnam National Foundation for Science and Technology Development (NAFOSTED) under grant number 104.05-2019.03.

\section{References}

[1] X. Huang and M. A. El-Sayed, "Gold nanoparticles: optical properties and implementations in cancer diagnosis and photothermal therapy," Journal of Advanced Research, vol. 1, no. 1, pp. 13-28, 2010.

[2] Y. Wu, M. R. K. Ali, K. Chen, N. Fang, and M. A. El-Sayed, "Gold nanoparticles in biological optical imaging," Nano Today, vol. 24, pp. 120-140, 2019.

[3] J. Wan, X. Ma, D. Xu, B. Yang, S. Yang, and S. Han, "Docetaxel-decorated anticancer drug and gold nanoparticles encapsulated apatite carrier for the treatment of liver cancer," Journal of Photochemistry and Photobiology B: Biology, vol. 185, pp. 73-79, 2018.

[4] Y. Zhang, T. P. Shareena Dasari, H. Deng, and H. Yu, "Antimicrobial activity of gold nanoparticles and ionic gold," Journal of Environmental Science and Health Part C, vol. 33, no. 3, pp. 286-327, 2015.

[5] M. J. Maleki, M. Pourhassan-Moghaddam, A. Karimi, A. Akbarzadeh, N. Zarghami, and S. A. Mohammadi, "Synthesis, characterisation, and application of chamomile gold nanoparticles in molecular diagnostics: a new component for PCR kits," Biointerface Research in Applied Chemistry, vol. 9, no. 6, pp. 4635-4641, 2019.

[6] T. A. Dobrovolskaya, V. M. Emelyanov, and V. V. Emelyanov, "Improving the accuracy of the solution of a multidimensional system by differentiating the XY probability density equations for the identification of gold nanoparticles on fibers," 2020Moscow Workshop on Electronic and Networking Technologies (MWENT), 2020.

[7] D. P. K. Samal, L. B. Sukla, A. Pattanaik, and D. Pradhan, "Extraction of gold from electronic scraps: a biohydrometallurgical process overview," Biointerface Research in Applied Chemistry, vol. 9, no. 5, pp. 4362-4367, 2019.

[8] L. F. de Freitas, G. Varca, J. dos Santos Batista, and A. B. Lugão, "An overview of the synthesis of gold nanoparticles using radiation technologies," Nanomaterials, vol. 8, no. 11, p. 939, 2018.

[9] M. Sengani, A. M. Grumezescu, and V. D. Rajeswari, "Recent trends and methodologies in gold nanoparticle synthesis - A prospective review on drug delivery aspect," Open Nano, vol. 2, pp. 37-46, 2017.

[10] I. Hussain, N. B. Singh, A. Singh, H. Singh, and S. C. Singh, "Green synthesis of nanoparticles and its potential application," Biotechnology Letters, vol. 38, no. 4, pp. 545-560, 2016.

[11] A. Gour and N. K. Jain, "Advances in green synthesis of nanoparticles," Artificial Cells, Nanomedicine, and Biotechnology, vol. 47, no. 1, pp. 844-851, 2019.

[12] Y. Guo, N. Jiang, L. Zhang, and M. Yin, "Green synthesis of gold nanoparticles from _Fritillaria cirrhosa_ and its antidiabetic activity on Streptozotocin induced rats," Arabian Journal of Chemistry, vol. 13, no. 4, pp. 5096-5106, 2020.

[13] S. Balasubramanian, S. M. J. Kala, and T. L. Pushparaj, "Biogenic synthesis of gold nanoparticles using Jasminum auriculatum leaf extract and their catalytic, antimicrobial and anticancer activities," Journal of Drug Delivery Science and Technology, vol. 57, p. 101620, 2020.

[14] M. Uzma, N. Sunayana, V. B. Raghavendra, C. S. Madhu, R. Shanmuganathan, and K. Brindhadevi, "Biogenic synthesis of gold nanoparticles using _Commiphora wightii_ and their cytotoxic effects on breast cancer cell line (MCF-7)," Process Biochemistry, vol. 92, pp. 269-276, 2020. 
[15] I. S. Unal, A. Demirbas, I. Onal, N. Ildiz, and I. Ocsoy, "One step preparation of stable gold nanoparticle using red cabbage extracts under UV light and its catalytic activity," Journal of Photochemistry and Photobiology B: Biology, vol. 204, article 111800, 2020.

[16] M. A. Rabeea, M. N. Owaid, A. A. Aziz, M. S. Jameel, and M. A. Dheyab, "Mycosynthesis of gold nanoparticles using the extract of _Flammulina velutipes_, Physalacriaceae, and their efficacy for decolorization of methylene blue," Journal of Environmental Chemical Engineering, no. article 103841, 2020.

[17] T. Zhang, M. Dang, W. Zhang, and X. Lin, "Gold nanoparticles synthesized from _Euphorbia fischeriana_ root by green route method alleviates the isoprenaline hydrochloride induced myocardial infarction in rats," Journal of Photochemistry and Photobiology B: Biology, vol. 202, article 111705, 2020.

[18] C. Vijilvani, M. R. Bindhu, F. C. Frincy et al., "Antimicrobial and catalytic activities of biosynthesized gold, silver and palladium nanoparticles from_Solanum nigurum_leaves," Journal of Photochemistry and Photobiology B: Biology, vol. 202, article 111713, 2020.

[19] A. Lione, "Handbook of Ayurvedic medicinal plants: Kapoor LD. Boca Raton, Florida, CRC Press, Inc.; 1990. 416 pages, \$195.00," Reproductive Toxicology, vol. 5, no. 1, p. 85, 1991.

[20] M. Kamle, D. K. Mahato, K. E. Lee et al., "Ethnopharmacological properties and medicinal uses of Litsea cubeba," Plants, vol. 8, no. 6, p. 150, 2019.

[21] L. Wang, W. Hu, J. Deng, X. Liu, J. Zhou, and X. Li, “Antibacterial activity ofLitsea cubebaessential oil and its mechanism againstBotrytis cinerea," RSC Advances, vol. 9, no. 50, pp. 28987-28995, 2019.

[22] G. B. Hong and C. J. Jiang, "Synthesis of $\mathrm{SnO}_{2}$ nanoparticles using extracts from _Litsea cubeba_fruits," Materials Letters, vol. 194, pp. 164-167, 2017.

[23] V. D. Doan, V. T. Le, T. D. Nguyen, T. L. H. Nguyen, and H. T. Nguyen, "Green synthesis of silver nanoparticles usingaganonerion polymorphumleaves extract and evaluation of their antibacterial and catalytic activity," Materials Research Express, vol. 6, no. 11, 2019.

[24] A. Singhal and A. Gupta, "Efficient utilization of Sal deoiled seed cake (DOC) as reducing agent in synthesis of silver nanoparticles: application in treatment of dye containing wastewater and harnessing reusability potential for cost-effectiveness," Journal of Molecular Liquids, vol. 268, pp. 691-699, 2018.

[25] S. Khan, W. Runguo, K. Tahir, Z. Jichuan, and L. Zhang, "Catalytic reduction of 4-nitrophenol and photo inhibition of _Pseudomonas aeruginosa_ using gold nanoparticles as photocatalyst," Journal of Photochemistry and Photobiology B: Biology, vol. 170, pp. 181-187, 2017.

[26] S. S. Hassan, K. Carlson, S. K. Mohanty, and A. C. Sirajuddin, "Ultra-rapid catalytic degradation of 4-nitrophenol with ionic liquid recoverable and reusable ibuprofen derived silver nanoparticles," Environmental Pollution, vol. 237, pp. 731-739, 2018.

[27] G. Wu, X. Liu, P. Zhou et al., "A facile approach for the reduction of 4-nitrophenol and degradation of congo red using gold nanoparticles or laccase decorated hybrid inorganic nanoparticles/polymer-biomacromolecules vesicles," Materials Science and Engineering: C, vol. 94, pp. 524-533, 2019.

[28] A. A. Al-Kahtani, T. Almuqati, N. Alhokbany, T. Ahamad, M. Naushad, and S. M. Alshehri, "A clean approach for the reduction of hazardous 4-nitrophenol using gold nanoparti- cles decorated multiwalled carbon nanotubes," Journal of Cleaner Production, vol. 191, pp. 429-435, 2018.

[29] T. M.-T. Nguyen, T. T.-T. Huynh, C.-H. Dang et al., "Novel biogenic silver nanoparticles used for antibacterial effect and catalytic degradation of contaminants," Research on Chemical Intermediates, vol. 46, no. 3, pp. 1975-1990, 2020.

[30] V.-D. Doan, V.-S. Luc, T. L.-H. Nguyen, T.-D. Nguyen, and T.-D. Nguyen, "Utilizing waste corn-cob in biosynthesis of noble metallic nanoparticles for antibacterial effect and catalytic degradation of contaminants," Environmental Science and Pollution Research, vol. 27, no. 6, pp. 61486162, 2020.

[31] A. Zuber, M. Purdey, E. Schartner et al., "Detection of gold nanoparticles with different sizes using absorption and fluorescence based method," Sensors and Actuators B: Chemical, vol. 227, pp. 117-127, 2016.

[32] N. K. R. Bogireddy, U. Pal, L. M. Gomez, and V. Agarwal, "Size controlled green synthesis of gold nanoparticles usingCoffea arabicaseed extract and their catalytic performance in 4nitrophenol reduction," RSC Advances, vol. 8, no. 44, pp. 24819-24826, 2018.

[33] Y. H. Yang, X. Z. Li, and S. Zhang, "Preparation methods and release kinetics ofLitsea cubebaessential oil microcapsules," RSC Advances, vol. 8, no. 52, pp. 29980-29987, 2018.

[34] A. Gangula, R. Podila, M. Ramakrishna, L. Karanam, C. Janardhana, and A. M. Rao, "Catalytic reduction of 4nitrophenol using biogenic gold and silver nanoparticles derived from Breynia rhamnoides," Langmuir, vol. 27, no. 24, pp. 15268-15274, 2011.

[35] K. Xin Lee, K. Shameli, M. Miyake et al., "Green synthesis of gold nanoparticles using aqueous extract of Garcinia mangostana fruit peels," Journal of Nanomaterials, vol. 2016, 7 pages, 2016.

[36] P. K. Francis, S. Sivadasan, A. Avarachan, and A. Gopinath, "A novel green synthesis of gold nanoparticles using seaweedLobophora variegataand its potential application in the reduction of nitrophenols," Particulate Science and Technology, vol. 38, no. 3, pp. 365-370, 2020.

[37] T.-T. Vo, C.-H. Dang, V.-D. Doan, V.-S. Dang, and T.D. Nguyen, "Biogenic synthesis of silver and gold nanoparticles from Lactuca indica leaf extract and their application in catalytic degradation of toxic compounds," Journal of Inorganic and Organometallic Polymers and Materials, vol. 30, no. 2, pp. 388-399, 2020.

[38] R. Majumdar, B. G. Bag, and P. Ghosh, “Mimusops elengi bark extract mediated green synthesis of gold nanoparticles and study of its catalytic activity," Applied Nanoscience, vol. 6, no. 4, pp. 521-528, 2016.

[39] Y. Cui, X. Guo, X. Lai et al., "Green synthesis of jujubepolysaccharide-stabilized gold nanoparticles for reduction of 4-nitrophenol," ChemistrySelect, vol. 4, no. 39, pp. 1148311487, 2019.

[40] Y. S. Seo, E. Y. Ahn, J. Park et al., "Catalytic reduction of 4-nitrophenol with gold nanoparticles synthesized by caffeic acid," Nanoscale Research Letters, vol. 12, no. 1, p. 7, 2017.

[41] W. Shen, Y. Qu, X. Pei et al., "Green synthesis of gold nanoparticles by a newly isolated strain Trichosporon montevideense for catalytic hydrogenation of nitroaromatics," Biotechnology Letters, vol. 38, no. 9, pp. 1503-1508, 2016. 
[42] Y. Qu, S. You, X. Zhang et al., "Biosynthesis of gold nanoparticles using cell-free extracts of Magnusiomyces ingens LH-F1 for nitrophenols reduction," Bioprocess and Biosystems Engineering, vol. 41, no. 3, pp. 359-367, 2018.

[43] T.-T. Vo, T. T.-N. Nguyen, T. T.-T. Huynh et al., "Biosynthesis of silver and gold nanoparticles using aqueous extract from Crinum latifolium leaf and their applications forward antibacterial effect and wastewater treatment," Journal of Nanomaterials, vol. 2019, 14 pages, 2019. 